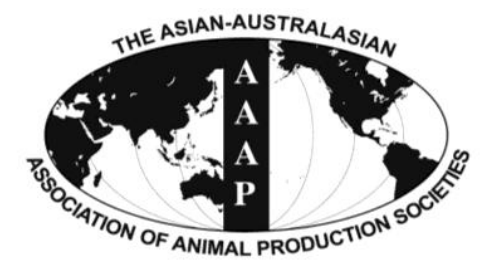

Asian Australas. J. Anim. Sci.

Vol. 26, No. 6 : 831-837 June 2013

http://dx.doi.org/10.5713/ajas.2012.12559

www.ajas.info

pISSN $1011-2367$ elSSN 1976-5517

\title{
The Effects of Rhodobacter capsulatus KCTC-2583 on Cholesterol Metabolism, Egg Production and Quality Parameters during the Late Laying Periods in Hens
}

\author{
Anushka Lokhande ${ }^{\text {a }}$, S. L. Ingale ${ }^{1, a}$, S. H. Lee ${ }^{1}$, J. S. Kim ${ }^{1}$, J. D. Lohakare ${ }^{2}$, B. J. Chae' ${ }^{1}$ and I. K. Kwon* \\ Department of Animal Products and Food Science, College of Animal Life Sciences, \\ Kangwon National University, Chuncheon 200-701, Korea
}

\begin{abstract}
An experiment was conducted to investigate the effects of dietary supplementation of Rhodobacter capsulatus KCTC2583 on egg-yolk and serum cholesterol, egg production and quality parameters during the late laying periods in hens. A total of $160 \mathrm{Hy}-$ Line Brown layers (54 wk-old) were randomly allotted to 4 treatment groups on the basis of laying performance. Each treatment had 4 replicates with 10 birds each (40 birds per treatment). Two hens were confined individually with cage size $35 \times 35 \times 40 \mathrm{~cm}$ and each 10 birds ( 5 cages) shared a common feed trough between them forming one experimental unit. Dietary treatments were; basal diet supplemented with 0 (control), 0.05, 0.10 and $0.15 \%$ R. capsulatus KCTC-2583. Experimental diets were fed in meal form for $56 \mathrm{~d}$. Dietary supplementation of increasing levels of $R$. capsulatus KCTC-2583 reduced (linear, p<0.05) egg-yolk cholesterol and triglycerides (d 28, 42 and 56) concentrations. Also, serum cholesterol and triglycerides (d 21, 42 and 56) concentrations were linearly reduced $(\mathrm{p}<0.05)$ with increasing dietary $R$. capsulatus KCTC-2583. Laying hens fed a diet supplemented with increasing levels of $R$. capsulatus KCTC-2583 had increased (linear; $\mathrm{p}<0.05$ ) overall egg production, egg weight, egg mass and feed efficiency. However, dietary treatments had no effect (linear or quadratic; $p>0.05$ ) on feed intake of laying hens. At d 28 and 56, breaking strength and yolk colour of eggs were linearly improved $(\mathrm{p}<0.05)$ in laying hens fed dietary increasing levels of $R$. capsulatus KCTC-2583. Dietary treatment had no effects (linear or quadratic; $p>0.05$ ) on albumin height, shell thickness and shell weight at any period of experiment. These results indicate that dietary supplementation of $R$. capsulatus KCTC-2583 has the potential to improve the laying hen performance and lead to the development of low cholesterol eggs during late laying period in Hy-Line Brown hens. (Key Words: Cholesterol, Egg Quality, Laying Hens, Performance, Rhodobacter capsulatus KCTC-2583)
\end{abstract}

\section{INTRODUCTION}

With growing concern over the relationship between diet and health, there is an increasing emphasis on modification of fat and cholesterol content of edible animals and poultry products. Chicken eggs are an excellent source of the many essential nutrients, like high quality protein,

\footnotetext{
* Corresponding Author: Ill-Kyong Kwon. Tel: +82-33-250-8644, Fax: +82-33-251-7719, E-mail: ikkwon@kangwon.ac.kr

${ }^{1}$ Department of Animal Resources Science, College of Animal Life Sciences, Kangwon National University, Chuncheon 200701, Korea.

${ }^{2}$ Department of Animal Biotechnology, College of Animal Life Sciences, Kangwon National University, Chuncheon 200-701, Korea.

a These authors contributed equally to this research and should considered co-first authors.

Submitted Oct. 9, 2012; Accepted Jan. 25, 2013; Revised Feb. 22, 2013
}

calcium, phosphorus, folic acid, $\alpha$-tocopherol and other B vitamins. However, chicken eggs yolk is rich source of cholesterol (213 mg/egg; USDA, 1991), which limit the consumption of eggs by health-conscious consumers to avoid hypercholesterolemia and heart related problems. Therefore, the research goals are directed towards the production of low cholesterol eggs. During past few decades, attempts to lowering egg-yolk cholesterol have centered mostly on genetic selection, pharmacological intervention or alteration of the laying hen diets with various nutrients like probiotics, nutraceuticals or nonnutritive factors. However, genetic selection had limited cholesterol reducing effect (Hollands et al., 1980; Ansah et al., 1985) and use of pharmaceuticals causes serious problem like drug residues in eggs (Salyers et al., 2004; Mathur and Singh, 2005). Therefore there is urgent need for developing the feed additives which can reduce the egg cholesterol without affecting the human health. 
Previous studies on dietary supplementation of chromium (Uyanik et al., 2002), copper (Balevi and Coskun, 2004), garlic paste (Chowdhury et al., 2002; Mottaghitalab and Taraz, 2002), omega-3 fatty acid (Lewis et al., 2000), tamarind (Chowdhury et al., 2005) had reported reduction in egg cholesterol or triglyceride concentrations. The dietary supplementation of the photosynthetic bacteria, a $R$. capsulatus also resulted in a marked reduction of egg-yolk or broiler meat cholesterol and triglyceride concentrations (Salma et al., 2007a;b). Tsujii et al. (2007) observed marked reduction in serum cholesterol in rat fed diets supplemented with $R$. capsulatus. Numerous studies have been conducted to determine the effects of various feed additives including $R$. capsulatus on performance and egg cholesterol during early laying period in hens. To our knowledge, the effect of $R$. capsulatus during late laying period has not been tested. Therefore, the objectives of present study were to investigate the effects of dietary supplementation of $R$. capsulatus KCTC-2583 on egg production, quality parameters and egg-yolk cholesterol during the late laying periods in Hy-Line Brown hens.

\section{MATERIAL AND METHODS}

The protocol for this experiment was approved and birds were cared according to the guidelines of the Institutional Animal Care and Use Committee of Kangwon National University, Chuncheon, Korea.

\section{Culture and preparation of Rhodobacter capsulatus KCTC-2583}

Rhodobacter capsulatus KCTC-2583 (Korean Collection for Type Culture-2583) used in the present study was obtained from the Biological Resource Center, Korea Research Institute of Bioscience and Biotechnology, Daejeon, Korea. The R. capsulatus KCTC-2583 cells were grown in outdoor culture under natural illuminations for 96 h. Briefly, cells of $R$. capsulatus KCTC-2583 were collected by centrifugation at $10,000 \times \mathrm{g}$ for $10 \mathrm{~min}$. The residual cell mass were mixed with corn meal (1:5) and dried using a forced-air drying oven at $60^{\circ} \mathrm{C}$ and stored at $4^{\circ} \mathrm{C}$. The viable cell count of $R$. capsulatus KCTC-2583 was $10^{8}$ $\mathrm{cfu} / \mathrm{g}$.

\section{Birds, diets and management}

A total of $160 \mathrm{Hy}$-Line Brown layers (54 wk-old) were randomly allotted to 4 treatment groups on the basis of laying performance. Each treatment had 4 replicates with 10 birds each (40 birds per treatment). Two hens were confined individually with cage size $35 \times 35 \times 40 \mathrm{~cm}$ and each 10 birds (5 cages) shared a common feed trough between them forming one experimental unit. Dietary treatments were; basal diet supplemented with 0 (control), 0.05, 0.10 and
$0.15 \% R$. capsulatus KCTC-2583. All the birds were fed isocaloric and isoprotineous diet in mash form for $56 \mathrm{~d}$. $R$. capsulatus KCTC-2583 product were added to basal diet by equally replacing corn. All the nutrients met or exceeded the nutrient requirements as recommended by NRC (1994) as shown in Table 1 . The birds were provided daily ad libitum feed and clean drinking water during $56 \mathrm{~d}$ feeding period. Laying hens were exposed to a 16-h incandescent light period.

\section{Sampling and measurement}

The laying hens were weighed at beginning and on $\mathrm{d} 28$ and 56 of experimental feeding. Daily egg production and egg weight per treatment group was recorded to determine the hen day egg production and the egg mass production

Table 1. Ingredient and chemical composition of basal diet (asfed basis) ${ }^{1}$

\begin{tabular}{lr}
\hline Items & Basal diet \\
\hline Ingredients (\%) & 48.13 \\
Corn & 5.00 \\
Wheat & 20.30 \\
Soybean meal (45\%) & 2.00 \\
Rape seed meal & 5.90 \\
Corn gluten meal & 3.00 \\
Distillers dried grains with solubles & 3.00 \\
Rice bran & 1.62 \\
Animal fat & 0.06 \\
Choline chloride (50\%) & 0.09 \\
L-Lysine (24\%) & 0.08 \\
Methionine hydroxyl analog $(88 \%)$ & 9.53 \\
Limestone & 0.76 \\
Dicalcium phosphate & 0.23 \\
Salt & 0.10 \\
NaHCO & 0.10 \\
Vitamin premix & \\
Mineral premix & \\
Chemical composition $(\%)$ & 0.10 \\
ME (kcal/kg) & \\
DM & \\
CP & 2,750 \\
Ash & 91.23 \\
Ca & 16.60 \\
Available P & 5.09 \\
Lysine & 4.02 \\
Met+cys & 0.30 \\
Cholesterol & 0.89 \\
\hline & 0.74 \\
\hline & 0.015 \\
\hline
\end{tabular}

${ }^{1}$ Dietary treatments were; basal diet supplemented with 0 (control), 0.05, 0.10 and $0.15 \%$ Rhodobacter capsulatus KCTC-2583.

${ }^{2}$ Supplied per kilogram of diet: 9,000 IU vitamin A, 1,800 IU vitamin $D_{3}$, 30 IU vitamin $\mathrm{E}, 1.5 \mathrm{mg}$ vitamin $\mathrm{K}_{3}, 1.5 \mathrm{mg}$ vitamin $\mathrm{B}_{1}, 5 \mathrm{mg}$ vitamin $\mathrm{B}_{2}, 4 \mathrm{mg}$ vitamin $\mathrm{B}_{6}, 0.025 \mathrm{mg}$ vitamin $\mathrm{B}_{12}, 15 \mathrm{mg}$ pantothenic acid, 35 $\mathrm{mg}$ niacin, $0.15 \mathrm{mg}$ biotin, $0.65 \mathrm{mg}$ folic acid, $12 \mathrm{mg}$ antioxidant.

${ }^{3}$ Supplied per kilogram of diet: $45 \mathrm{mg} \mathrm{Fe}$ as ferrous sulfate, $0.25 \mathrm{mg}$ Co as cobalt sulfate, $50 \mathrm{mg} \mathrm{Cu}$ as copper sulfate, $15 \mathrm{mg} \mathrm{Mn}$ as manganous oxide, $25 \mathrm{mg} \mathrm{Zn}$ as zinc oxide, $0.35 \mathrm{mg} \mathrm{I}$ as potassium iodide and 0.13 $\mathrm{mg}$ Se as sodium selenite. 
$(\mathrm{g} / \mathrm{d} / \mathrm{hen})$. Feed intake was recorded weekly and feed conversion efficiency (feed intake:egg mass) was calculated during $56 \mathrm{~d}$ feeding period. Eggs from each group were collected at beginning and at 2 wks interval during feeding period for measuring egg quality (egg weight, shell weight, shell thickness, yolk colour, and Haugh unit) and for analysis of yolk cholesterol and triglyceride. Egg shell breaking strength $\left(\mathrm{kg} / \mathrm{m}^{2}\right)$ was measured by using texture analyzer (FHK Fujihira Industry co. LTD, Japan). The egg was laid in vertical position on pan of texture analyzer was squeezed and the shell hardness was measured. Yolk colour was evaluated by using colorimetric fan (Roche) and scored according to their intensity. Egg shell weight was measured using electric weighing balance.

At the beginning and on $\mathrm{d} 21,42$ and 56 of experimental feeding, a $5 \mathrm{ml}$ blood sample was collected by bronchial wing vein puncture from 2 randomly selected hens in each group using sterilized syringes and needles. After $90 \mathrm{~min}$ standing at room temperature, serum was isolated by centrifugation at $3,000 \times \mathrm{g}$ for $15 \mathrm{~min}$. Separated serum samples were stored at $-80^{\circ} \mathrm{C}$ and later analysed for concentrations of total cholesterol and triglycerides.

\section{Extraction of yolk and diet lipid}

One gram of egg-yolk was placed into a centrifuge tube and mixed with $15 \mathrm{ml}$ of chloroform:methanol $(2: 1 \mathrm{v} / \mathrm{v})$, sonicated and filtered as described by Elkin and Rogler, (1990). Dietary lipid were extracted by same procedure using 5-g feed sample with $40 \mathrm{ml}$ of chloroform:methanol.

\section{Chemical and enzymatic analysis}

Experimental diet was analysed in triplicate for DM (Method 930.15), CP (Method 990.03), ash (Method
942.05), Ca and P (Method 985.01) using AOAC (2007). Gross energy of experimental diet was measured by a bomb calorimeter (Model 1216, Parr Instrument Co., Moline, IL, USA). Total cholesterol and triglycerides in the serum and egg-yolk were determined enzymatically using commercial reagent kits (ASAN Total Cholesterol, AM 202-K and ASAN TG-S, AM 157S-K, respectively, ASAN Pharm. Co. Ltd., Geonggi-do, Korea).

\section{Statistical analysis}

The data generated in present study was subjected to statistical analysis using GLM procedure of SAS (SAS Inst. Inc., Cary, NC, USA) in a randomized complete block design. The orthogonal polynomials were used to evaluate the linear and quadratic effects of dietary $R$. capsulatus KCTC-2583 levels $(0,0.25,0.50$ and $0.75 \%)$. For analysis of egg and serum cholesterol and triglycerides, individual egg and hen were used as experimental unit respectively. For analysis of production performance parameters, a replicate of 10 birds was used as experimental unit. Probability values of less than $0.05 \quad(p<0.05)$ were considered significant.

\section{RESULTS}

\section{Egg yolk cholesterol and triglycerides}

Dietary supplementation of increasing level of R. capsulatus KCTC-2583 reduced (linear, $\mathrm{p}<0.05$; Table 2) eggs cholesterol and triglycerides (d 28, 42 and 56) concentrations. At d 56, reduction of egg-yolk cholesterol were $9.33,13.56$ and $19.29 \%$ in laying hen fed diet supplemented with $0.05,0.10$ and $0.15 \% R$. capsulatus KCTC-2583, respectively, as compared to laying hens fed

Table 2. Effects of dietary supplementation of Rhodobacter capsulatus KCTC-2583 on egg-yolk cholesterol and triglyceride concentrations in laying hen ${ }^{1}$

\begin{tabular}{|c|c|c|c|c|c|c|c|}
\hline & \multicolumn{4}{|c|}{ R. capsulatus KCTC-2583 (\%) } & \multirow{2}{*}{ SEM } & \multicolumn{2}{|c|}{ p-value ${ }^{2}$} \\
\hline & 0 (Control) & 0.05 & 0.10 & 0.15 & & Linear & Quadratic \\
\hline \multicolumn{8}{|l|}{ Yolk cholesterol (mg/g) } \\
\hline d 0 & 15.78 & 15.85 & 15.75 & 15.67 & 0.12 & 0.725 & 0.774 \\
\hline d 14 & 15.38 & 14.91 & 14.77 & 14.65 & 0.18 & 0.183 & 0.762 \\
\hline d 28 & 15.29 & 14.34 & 14.13 & 13.85 & 0.21 & 0.013 & 0.349 \\
\hline d 42 & 15.36 & 14.00 & 13.68 & 12.99 & 0.34 & 0.013 & 0.563 \\
\hline d 56 & 15.55 & 14.10 & 13.44 & 12.56 & 0.35 & 0.001 & 0.564 \\
\hline$\%$ reduction $(\mathrm{d} 56)$ & 0.0 & 9.33 & 13.56 & 19.29 & 2.18 & 0.001 & 0.564 \\
\hline \multicolumn{8}{|l|}{ Yolk triglyceride $(\mathrm{mg} / \mathrm{g})$} \\
\hline $\mathrm{d} 0$ & 254.47 & 257.85 & 252.08 & 254.74 & 4.24 & 0.888 & 0.963 \\
\hline d 14 & 251.19 & 242.23 & 237.49 & 232.84 & 5.72 & 0.061 & 0.744 \\
\hline d 28 & 253.35 & 235.84 & 232.12 & 224.67 & 4.84 & 0.031 & 0.551 \\
\hline $\mathrm{d} 42$ & 245.91 & 222.33 & 216.65 & 207.58 & 5.25 & 0.017 & 0.469 \\
\hline d 56 & 247.19 & 219.14 & 206.88 & 201.42 & 6.16 & 0.001 & 0.105 \\
\hline$\%$ reduction $(\mathrm{d} 56)$ & 0.0 & 11.35 & 16.31 & 18.52 & 2.27 & 0.001 & 0.105 \\
\hline
\end{tabular}

${ }^{1}$ Values are the mean of 5 eggs per treatment.

${ }^{2}$ Linear and quadratic effect of increasing dietary levels of Rhodobacter capsulatus KCTC-2583 (0, 0.05, 0.10 and $0.15 \%$ of basal diet). 
Table 3. Effects of dietary supplementation of Rhodobacter capsulatus KCTC-2583 on serum cholesterol and triglycerides concentrations in laying hen ${ }^{1}$

\begin{tabular}{|c|c|c|c|c|c|c|c|}
\hline & \multicolumn{4}{|c|}{ R. capsulatus KCTC-2583 (\%) } & \multirow{2}{*}{ SEM } & \multicolumn{2}{|c|}{ p-value ${ }^{2}$} \\
\hline & 0 (Control) & 0.05 & 0.01 & 0.15 & & Linear & Quadratic \\
\hline \multicolumn{8}{|c|}{ Serum cholesterol (mmol/L) } \\
\hline $0 \mathrm{~d}$ & 4.61 & 4.56 & 4.59 & 4.67 & 0.04 & 0.637 & 0.498 \\
\hline d 21 & 4.88 & 4.63 & 4.55 & 4.32 & 0.07 & 0.020 & 0.890 \\
\hline $\mathrm{d} 42$ & 4.65 & 4.32 & 4.10 & 3.88 & 0.10 & 0.003 & 0.742 \\
\hline d 56 & 4.86 & 4.37 & 4.09 & 3.85 & 0.12 & 0.001 & 0.395 \\
\hline$\%$ reduction $(\mathrm{d} 56)$ & 0.00 & 10.05 & 15.78 & 20.82 & 2.38 & 0.001 & 0.395 \\
\hline \multicolumn{8}{|c|}{ Serum triglyceride $(\mathrm{mmol} / \mathrm{L})$} \\
\hline $0 \mathrm{~d}$ & 5.24 & 5.20 & 5.13 & 5.17 & 0.05 & 0.311 & 0.519 \\
\hline d 21 & 5.28 & 4.98 & 4.84 & 4.62 & 0.09 & 0.020 & 0.645 \\
\hline d 42 & 5.22 & 4.81 & 4.55 & 4.39 & 0.15 & 0.001 & 0.169 \\
\hline d 56 & 5.31 & 4.61 & 4.38 & 4.19 & 0.19 & 0.001 & 0.198 \\
\hline$\%$ reduction $(\mathrm{d} 56)$ & 0.00 & 13.26 & 17.59 & 21.11 & 2.15 & 0.001 & 0.198 \\
\hline
\end{tabular}

${ }^{1}$ Values are the mean of 5 hens per treatment

${ }^{2}$ Linear and quadratic effect of increasing dietary levels of $R$. capsulatus KCTC-2583 (0, 0.05, 0.10 and $0.15 \%$ of basal diet).

control diet. Whereas, percent reduction in yolk triglycerides at $\mathrm{d} 56$ were, $11.35,16.31$ and 18.52 in laying hen fed dietary $0.05,0.10$ and $0.15 \%$ R. capsulatus KCTC2583 , respectively.

\section{Serum cholesterol and triglycerides}

Serum cholesterol and triglycerides (d 21, 42 and 56) concentrations were linearly reduced $(p<0.05$ : Table 3 ) with increasing dietary levels of $R$. capsulatus KCTC-2583. At d
56 , hens fed dietary $0.05,0.10$ or $0.15 \% R$. capsulatus KCTC-2583 had $10.05,15.78$ and $20.82 \%$ reduction in serum cholesterol, respectively. Percent reduction in yolk triglycerides at d 56 were, 13.26, 17.59 and 21.11, respectively, in laying hen fed dietary $0.05,0.10$ and $0.15 \%$ R. capsulatus KCTC-2583.

\section{Layer performance}

Laying hens fed diet supplemented with increasing

Table 4. Effects of dietary supplementation of Rhodobacter capsulatus KCTC-2583 on egg production, egg weight, egg mass, feed intake and feed efficiency in laying hens ${ }^{1}$

\begin{tabular}{|c|c|c|c|c|c|c|c|}
\hline \multirow{2}{*}{ Item } & \multicolumn{4}{|c|}{ R. capsulatus KCTC-2583 (\%) } & \multirow{2}{*}{ SEM } & \multicolumn{2}{|c|}{$\mathrm{p}$ values $^{2}$} \\
\hline & 0 (Control) & 0.05 & 0.10 & 0.15 & & Linear & Quadratic \\
\hline \multicolumn{8}{|l|}{1 to $4 \mathrm{wk}$} \\
\hline Egg production (\%) & 77.23 & 77.32 & 77.72 & 78.75 & 0.23 & 0.111 & 0.745 \\
\hline Egg weight (g) & 60.71 & 62.32 & 62.88 & 63.18 & 0.32 & 0.021 & 0.230 \\
\hline $\operatorname{Egg~mass~}^{3}(\mathrm{~g} / \mathrm{d} / \mathrm{hen})$ & 46.88 & 48.18 & 48.86 & 49.74 & 0.32 & 0.010 & 0.456 \\
\hline Feed intake $(\mathrm{g} / \mathrm{d} / \mathrm{hen})$ & 124.82 & 124.64 & 123.88 & 124.35 & 0.38 & 0.277 & 0.577 \\
\hline Feed efficiency ${ }^{4}$ & 2.66 & 2.59 & 2.54 & 2.50 & 0.02 & 0.019 & 0.477 \\
\hline \multicolumn{8}{|l|}{5 to $8 \mathrm{wk}$} \\
\hline Egg production (\%) & 76.61 & 77.68 & 78.39 & 79.64 & 0.22 & 0.075 & 0.856 \\
\hline Egg weight (g) & 63.04 & 63.68 & 64.17 & 64.48 & 0.41 & 0.007 & 0.388 \\
\hline Egg mass (g/d/hen) & 48.29 & 49.47 & 50.29 & 51.35 & 0.45 & 0.042 & 0.915 \\
\hline Feed intake $(\mathrm{g} / \mathrm{d} / \mathrm{hen})$ & 124.56 & 123.13 & 122.49 & 122.24 & 0.51 & 0.111 & 0.572 \\
\hline Feed efficiency & 2.58 & 2.49 & 2.44 & 2.38 & 0.02 & 0.003 & 0.635 \\
\hline \multicolumn{8}{|l|}{ Overall (1 to 8 wk) } \\
\hline Egg production (\%) & 76.92 & 77.50 & 78.06 & 79.20 & 0.17 & 0.021 & 0.752 \\
\hline Egg weight (g) & 61.87 & 63.00 & 63.53 & 63.83 & 0.24 & 0.001 & 0.107 \\
\hline Egg mass (g/d/hen) & 47.59 & 48.83 & 49.58 & 50.55 & 0.27 & 0.010 & 0.661 \\
\hline Feed intake $(\mathrm{g} / \mathrm{d} / \mathrm{hen})$ & 124.69 & 123.89 & 123.18 & 123.29 & 0.42 & 0.067 & 0.425 \\
\hline Feed efficiency & 2.62 & 2.54 & 2.48 & 2.44 & 0.02 & 0.001 & 0.416 \\
\hline
\end{tabular}

\footnotetext{
${ }^{1}$ All measurements were done as fresh basis; values are mean of 4 replicates of 10 hens each.

${ }^{2}$ Linear and quadratic effect of increasing dietary levels of $R$. capsulatus KCTC-2583 (0, 0.05, 0.10 and $0.15 \%$ of basal diet).

${ }^{3}$ Egg mass $=($ egg production $\times$ egg weight $) / 100 .{ }^{4}$ Feed efficiency $=$ Feed intake:egg mass $(\mathrm{g}: \mathrm{g})$.
} 
levels of $R$. capsulatus KCTC-2583 had better (linear; $\mathrm{p}<0.05$; Table 4) overall egg production, egg weight, egg mass and feed efficiency. However, dietary treatments had no effect (linear or quadratic; $p>0.05$ ) on feed intake of laying hens. Mortality was $0 \%$ in all groups during the experimental period.

\section{Egg quality}

At d 28 and 56, breaking strength and yolk colour of eggs were linearly improved ( $p<0.05$; Table 5) in laying hens fed diet supplemented with increasing levels of $R$. capsulatus KCTC-2583. Dietary treatment had no effects (linear or quadratic; p>0.05) on albumin height, shell thickness and shell weight at any period of experiment.

\section{DISCUSSION}

Previous attempts to reduce the egg-yolk cholesterol were mainly focused on the inclusion of pharmaceutical drugs and other agents to laying hens diets (Nobel, 1987; Hargis, 1988). However, occurrence of drug residues in eggs and the high cost of the pharmaceuticals limit their use as cholesterol reducing agents. As a result, poultry industry must focus on alternative to pharmaceutical drugs for reducing the egg-yolk cholesterol under commercial condition. In this sense, the photosynthetic bacteria of genus Rhodobacter had emerged as effective feed additive to reduce the cholesterol contents of egg-yolk (Salma et al., 2007a) and serum (Tsujii et al., 2007). In present study, we supplemented $R$. capsulatus KCTC-2583 to laying hen diets during their late laying cycle and its effects on cholesterol metabolism and laying performance were investigated.

The reduced cholesterol concentrations in serum and egg-yolk of the laying hens fed diets supplemented with increasing levels of $R$. capsulatus KCTC-2583 observed in the present study is in good agreement with data reported by the Salma et al. (2007a), who observed linear reduction of egg-yolk and serum cholesterol concentrations in hens fed diet supplemented with increasing levels $(0.01,0.02$ and $0.04 \%$ ) of $R$. capsulatus. Similarly, it was reported that laying hens fed diet supplemented with combination of $R$. capsulatus and karaya saponin had reduced serum (32\%) and egg-yolk cholesterol (18\%) concentrations (Afrose et al., 2010). Chowdury et al. (2002;2005) and Shim et al. (2004) observed reduction in egg yolk cholesterol in laying hens fed diet supplemented with garlic, tamarind and Codonopsis lanceolata roots, respectively. Observations made in the present study, Salma et al. (2007a) and Afrose et al. (2010) reveal that the cholesterol concentration in eggyolk has a positive correlation with change of the cholesterol content of the serum. In present study, after $56 \mathrm{~d}$ feeding, there were $9.33,13.56$ and $19.29 \%$ reduction in egg-yolk cholesterol and 10.05, 15.78 and $20.82 \%$ reduction of serum cholesterol, respectively in hens fed diet

Table 5. Effects of dietary Rhodobacter capsulatus KCTC-2583 on egg quality (breaking strength, albumin height, shell thickness, yolk colour and shell weight) at different interval in laying hen ${ }^{1}$

\begin{tabular}{|c|c|c|c|c|c|c|c|}
\hline & \multicolumn{4}{|c|}{ R. capsulatus KCTC-2583 (\%) } & \multirow{2}{*}{ SEM } & \multicolumn{2}{|c|}{$\mathrm{p}$ value $^{2}$} \\
\hline & 0 (Control) & 0.05 & 0.1 & 0.15 & & Linear & Quadratic \\
\hline \multicolumn{8}{|c|}{$\overline{\text { Breaking strength }\left(\mathrm{kg} / \mathrm{m}^{2}\right)}$} \\
\hline $0 \mathrm{~d}$ & 3.78 & 3.74 & 3.73 & 3.75 & 0.11 & 0.571 & 0.605 \\
\hline $4 \mathrm{wk}$ & 3.79 & 3.9 & 4.08 & 4.19 & 0.20 & 0.009 & 0.687 \\
\hline $8 \mathrm{wk}$ & 3.83 & 4.02 & 4.16 & 4.16 & 0.15 & 0.032 & 0.436 \\
\hline \multicolumn{8}{|c|}{ Albumin height (mm) } \\
\hline $0 \mathrm{~d}$ & 7.93 & 7.83 & 8.00 & 7.92 & 0.13 & 0.756 & 0.779 \\
\hline $4 \mathrm{wk}$ & 8.58 & 8.75 & 8.91 & 8.80 & 0.16 & 0.794 & 0.836 \\
\hline $8 \mathrm{wk}$ & 8.66 & 8.88 & 9.07 & 9.03 & 0.11 & 0.559 & 0.791 \\
\hline \multicolumn{8}{|c|}{ Yolk color (Roche color fan scale) } \\
\hline $0 \mathrm{~d}$ & 7.4 & 7.6 & 7.8 & 7.4 & 0.17 & 0.876 & 0.305 \\
\hline $4 \mathrm{wk}$ & 7.8 & 8.2 & 8.6 & 8.8 & 0.22 & 0.063 & 0.793 \\
\hline 8 wk & 8 & 8.6 & 9.2 & 9.4 & 0.22 & 0.006 & 0.564 \\
\hline \multicolumn{8}{|c|}{ Shell thickness (mm) } \\
\hline $0 \mathrm{~d}$ & 0.39 & 0.40 & 0.41 & 0.38 & 0.04 & 0.512 & 0.176 \\
\hline $4 \mathrm{wk}$ & 0.39 & 0.41 & 0.39 & 0.41 & 0.05 & 0.505 & 0.813 \\
\hline $8 \mathrm{wk}$ & 0.39 & 0.41 & 0.40 & 0.41 & 0.05 & 0.440 & 0.728 \\
\hline \multicolumn{8}{|c|}{ Shell weight (g) } \\
\hline $0 \mathrm{~d}$ & 7.14 & 7.21 & 7.22 & 7.04 & 0.14 & 0.677 & 0.731 \\
\hline $4 \mathrm{wk}$ & 7.17 & 7.36 & 7.44 & 7.47 & 0.12 & 0.432 & 0.767 \\
\hline $8 \mathrm{wk}$ & 7.10 & 7.32 & 7.44 & 7.48 & 0.15 & 0.280 & 0.728 \\
\hline
\end{tabular}

\footnotetext{
${ }^{1}$ All measurements were done as fresh basis; values are mean of 5 eggs per treatment.
}

${ }^{2}$ Linear and quadratic effect of increasing dietary levels of $R$. capsulatus KCTC-2583 (0, 0.05, 0.10 and $0.15 \%$ of basal diet). 
supplemented with $0.05,0.10$ and $0.15 \% R$. capsulatus KCTC-2583. However, in Salma et al. (2007a) study dietary supplementation of $0.04 \%$ R. capsulatus had $15 \%$ reduction in eggs-yolk cholesterol. The variation in the reduction in egg-yolk cholesterol in different studies might be due to variation in dose of the $R$. capsulatus and age of the hens. In present study we used hens in their late laying cycles (54 wk), whereas Samla et al. (2007a) and Afrose et al. (2010) used hens in early laying cycle ( 20 to $23 \mathrm{wk}$ ).

In this study, after $56 \mathrm{~d}$ of experimental feeding, hens fed diet supplemented with $0.05,0.10$ and $0.15 \% R$. capsulatus KCTC-2583 had reduced serum (13.26, 17.59 and $21.11 \%$, respectively) and egg-yolk triglycerides (11.35, 16.36 and $18.52 \%$, respectively) concentrations than hens fed diet without $R$. capsulatus KCTC-2583. Present findings are consistent with data reported by Salma et al. (2007a), who observed reduction in serum and egg-yolk triglycerides in laying hens fed diet supplemented with increasing levels $(0.01,0.02$ and 0.04$)$ of $R$. capsulatus during their early laying period. Similarly, Tsujii et al. (2007) reported reduced serum triglycerides concentration in rats fed diet supplemented with $R$. capsulatus. Lee et al. (1990) also reported similar results in rats fed diet supplemented with Rhodopseudomonas palustris.

Many pathways and factors have been reported to contribute to the hypocholesterolemic and other beneficiary effects of $R$. capsulatus, which were not clearly understood. Kobayashi and Kurata (1978) reported that $R$. capsulatus contains $4.2 \%$ carotenoids, which are know as hypocholesterolemic agent. Hypocholesterolemic effects in the present study might be due to carotenoids content of the $R$. capsulatus KCTC-2583. Some of the previous studies reported reduced serum cholesterol concentrations in rats fed carotenoid-rich diet (Amen and Lachance, 1974; Yeum and Rusell, 2002). In addition, it has reported that $R$. capsulatus contains many known and unknown factors, which might be associated with the improved performance and hypocholesterolemic effects (Salma et al., 2007a). A $R$. capsulatus are rich source of minerals $(\mathrm{Mg}, \mathrm{Mn}, \mathrm{Fe}$, and $\mathrm{Cu}$ etc), amino acids (arginine, glycine and lysine), vitamins (B2, B6, folic acid, C, E) and most of them were demonstrated to be cholesterol lowering effects (Vahouny et al., 1984; Ouchi et al., 1990; Phonpanichrasamee et al., 1990; Bakalli et al., 1995). A Rhodobacter may change the enzymes, which are associated in regulating the cholesterol synthesis, oxidation or elimination for lowering the cholesterol in laying hens, which might be responsible for hypocholesterolemic effect of $R$. capsulatus KCTC-2583 used in the present study.

In the present study, dietary supplementation of increasing levels of $R$. capsulatus KCTC-2583 had linear improvement in overall egg production, egg weight, egg mass and had better feed efficiency. In contrast to the present results, Salma et al. (2007a) reported no effects of dietary increasing levels of $R$. capsulatus on egg production, egg weight, egg mass and feed efficiency. This variation in results might be variation in age of hens, strain of $R$. capsulatus and dose of dietary supplementation. The levels of $R$. capsulatus KCTC-2583 used in our study (0, 0.05, 0.10 and $0.15 \%$ ) were much greater than the levels of $R$. capsulatus $(0,0.01,0.02$ and 0.04$)$ used by Salma et al. (2007a). In this study, dietary treatments had no effect on feed intake, which is in good agreement with data reported by Salma et al. (2007a), who also observed no effect of dietary $R$. capsulatus on feed intake of laying hens. Improved laying performance in present study might be due to cumulative effect of probiotics like action of $R$. capsulatus KCTC-2583, including improvement in nutrient digestion (Choi et al., 2011; Sen et al., 2011; Kim et al., 2012), maintenance of beneficial microbial population (Fuller, 1989; Sen et al., 2012) or alteration of bacterial metabolism (Jin et al., 1997; Choi et al., 2011). Increased feed efficiency in our study is due to increased egg production without affecting the feed intake.

In this study, supplementation of $R$. capsulatus KCTC2583 to laying hen diet during the late laying period improved the yolk color and the breaking strength of the eggs. The present findings are in good agreement with results of Salma et al. (2007a), who observed improvement is egg yolk color in laying hens fed increasing levels of the $R$. capsulatus. The improved yolk color in present study and Salma et al. (2007a) report might be due to high carotenoids content of the $R$. capsulatus. Previous study with dietary supplementation of external carotenoids reported improved carotenoids content and pigmentation of eggs in quail (Karadas et al., 2006).

In conclusion, results obtained in the present study indicated that dietary supplementation of $R$. capsulatus KCTC-2583 had potential to improve the laying hen performance and lead to the development of low cholesterol eggs during late laying period in Hy-Line Brown hens. However, further studies are needed to indentify the exact mechanism of hypocholesterolemic effect of $R$. capsulatus KCTC-2583.

\section{REFERENCES}

Afrose, S., M. S. Hossain, T. Maki and H. Tsujii. 2010. Effects of karaya saponin and Rhodobacter capsulatus on yolk cholesterol in laying hens. Br. Poult. Sci. 51:409-418.

Amen, R. J. and P. A. Lachance. 1974. The effect of betacarotene and canthaxanthin on serum cholesterol levels in the rat. Nutr. Rep. Int. 10:269-276.

Ansah, G. A., C. W. Chan, S. P. Touchburn and R. B. Buckland. 1985. Selection for low yolk cholesterol in Leghorn-type chickens. Poult. Sci. 64:1-5.

AOAC International. 2007. Official methods of analysis of AOAC 
International. $18^{\text {th }}$ ed. AOAC International, Gaithersburg, MD.

Bakalli, R. I., G. M. Pesti, W. L. Ragland and V. Konjufca. 1995. Dietary copper in excess of nutritional requirement reduces plasma and breast muscle cholesterol of chicken. Poult. Sci. 74:360-365.

Balevi, R. and B. Coskun. 2004. Effects of dietary copper on production and egg cholesterol content in laying hens. Br. Poult. Sci. 45:530-534.

Choi, J. Y., J. S. Kim, S. L. Ingale, K. H. Kim, P. L. Shinde, I. K. Kwon and B. J. Chae. 2011. Effect of potential multi-microbe probiotic product processed by high drying temperature and antibiotic on performance of weanling pigs. J. Anim. Sci. 89:1795-1804.

Choi, J. Y., P. L. Shinde, S. L. Ingale, J. S. Kim, Y. W. Kim, K. H. Kim, I. K. Kwon and B. J. Chae. 2011. Evaluation of multimicrobe probiotics prepared by submerged liquid or solid substrate fermentation and antibiotics in weaning pigs. Livest. Sci. 138:144-151.

Chowdhury, S. R., D. K. Sarker, S. D. Chowdhury, T. K. Smith, P. K. Roy and M. A. Wahid. 2005. Effects of dietary tamarind on cholesterol metabolism in laying hens. Poult. Sci. 84:56-60.

Chowdhury, S. R., S. D. Chowdhury and T. K. Smith. 2002. Effects of garlic on cholesterol metabolism in laying hens. Poult. Sci. 81:1856-1862.

Elkin, R. G. and J. C. Rogler. 1990. Reduction of the cholesterol content of eggs by the oral administration of lovastatin to laying hens. J. Agric. Food Chem. 38:1635-1641.

Fuller, R. 1989. Probiotics in man and animals. J. Appl. Bacteriol. 66:365-378

Hargis, P. S. 1988. Modifying egg yolk cholesterol in domestic fowl-A review. World's Poult. Sci. J. 44:17-29.

Hollands, K. G., A. A. Grunder and C. J. Williams. 1980. Response to five generations of selection for blood cholesterol levels in White Leghorns. Poult. Sci. 59:1316-1323.

Jin, L. Z., H. W. Ho, N. Abdullah and S. Jalaludin. 1997. Probiotics in poultry: Modes of action. World's Poult. Sci. J. 53:351-368

Karadas, F., E. Grammenidis, P. F. Surai, T. Acamovic and N. H. Sparks. 2006. Effects of carotenoids from lucerne, marigold and tomato on egg yolk pigmentation and carotenoid composition. Br. Poult. Sci. 47:561-666.

Kim, J. S., S. L. Ingale, Y. W. Kim, K. H. Kim, Sinol Sen, M. H. Ryu, J. D. Lohakare, I. K. Kwon and B. J. Chae. 2012. Effect of supplementation of multi-microbe probiotic product on growth performance, apparent digestibility, cecal microbiota and small intestinal morphology of broilers. J. Anim. Physiol. Anim. Nutr. 96:618-626.

Kobayashi, M. and S. Kurata. 1978. The mass culture and cell utilization of photosynthetic bacteria. Process Biochem. 9:2729.

Lee, M. G., M. Kobayashi and K. Yasumoto. 1990. Hypocholesterolemic effect of phototropic bacterial cells in rats. J. Nutr. Sci. Vitaminol. 36:475-483.

Lewis, N. M., S. Seburg, and N. L. Flanagan. 2000. Enriched eggs as a source of n-3 polyunsaturated fatty acids for humans. Poult. Sci. 79:971-974.

Mathur, S. and R. Singh. 2005. Antibiotic resistance in food lactic acid bacteria- a review. Int. J. Food Microbiol. 105:281-295.

Mottaghitalab, M. and Z. Taraz. 2002. Effects of garlic powder
(Allium sativum) on egg yolk and blood serum cholesterol in Aryan breed laying hens. Br. Poult. Sci. 43:S42-S43.

Noble, R. C. 1987. Egg lipids. Pages 159-177 in Egg quality current problems and recent advances. R. G. Wells and C. G. Belyavin, ed. Butterworths, London, UK.

NRC. 1994. Nutrient Requirement of Poultry. 9th Edn. National Academy Press, Washington, DC, USA.

Ouchi, Y., R. E. Tabata, K. Stergiopoulos, F. Sato, A. Hattori and H. Orimo. 1990. Effect of dietary magnesium on development of atherosclerosis in cholesterol-fed rabbits. Arteriosclerosis 10:732-737.

Phonpanichrasamee, C., P. Komaratat and P. Wilairat. 1990. Hypocholesterolemic effect of vitamin E on cholesterol-fed rabbit. Int. J. Vitam. Nutr. Res. 60:240-244.

Salma, U., A. G. Miah, K. M. A. Tareq, T. Maki and H. Tsujii. 2007a. Effect of dietary Rhodobacter capsulatus on egg-yolk cholesterol and laying hen performance. Poult. Sci. 86:714-719.

Salma, U., A. G. Miah, T. Maki, M. Nishimura and H. Tsujii. 2007b. Effect of dietary Rhodobacter capsulatus on cholesterol concentration and fatty acid composition in broiler meat. Poult. Sci. 86:1920-1926.

Salyers, A. A., A. Gupta and Y. Wang. 2004. Human intestinal bacteria as reservoirs for antibiotic resistance genes. Trends Microbiol. 12:412-416.

Sen Sinol, S. L. Ingale, Y. W. Kim, J. S. Kim, K. H. Kim, J. D. Lohakare, E. K. Kim, H. S. Kim, M. H. Ryu, I. K. Kwon and B. J. Chae. 2012. Effect of supplementation of Bacillus subtilis LS 1-2 to broiler diets on growth performance, nutrient retention, caecal microbiology and small intestinal morphology. Res. Vet. Sci. 93:264-268.

Sen Sinol, S. L. Ingale, J. S. Kim, K. H. Kim, Y. W. Kim, C. Khong, J. D. Lohakare, E. K. Kim, H. S. Kim, I. K. Kwon and B. J. Chae. 2011. Effect of supplementation of Bacillus subtilis LS 1-2 grown on citrus-juice waste and corn-soybean meal substrate on growth performance, nutrient retention, caecal microbiology and small intestinal morphology of broilers. Asian Australas. J. Anim. Sci. 24:1120-1127.

Shim, K. S., G. H. Park, C. J. Choi and C. S. Na. 2004. Decreased triglyceride and cholesterol levels in serum, liver and breast muscle in broiler by the supplementation of dietary Codonopsis lanceolata root. Asian Australas. J. Anim. Sci. 17:511-513.

Tsujii, H., M. Nishioka, U. Salma, A. G. Miah, T. Maki, and M. G. Lee. 2007. Comparative study on hypocholesterolemic effect of Rhodopseudomonas palustris and Rhodobacter capsulatus on rats fed a high-cholesterol diet. Anim. Sci. J. 78:535-540.

USDA. 1991. Nutrient content of foods. Dairy and Egg Products Handbook 8-1. USDA, Washington, DC, USA.

Uyanik, F., S. Kaya, A. H. Kolsuz, M. Eren and N. Sahin. 2002. The effect of chromium supplementation on egg production, egg quality and some serum parameters in laying hens. Turk. J. Vet. Anim. Sci. 26:379-387.

Vahouny, G. V., W. Chalcarz, S. Satchithanandam, I. Adamson, D. Klurfeld and D. Kritchevsky. 1984. Effect of soy protein and casein intake on intestinal absorption and lymphatic transport of cholesterol and oleic acid. Am. J. Clin. Nutr. 40:1156-1164.

Yeum, K. J. and R. M. Russell. 2002. Carotenoid bioavailability and bioconversion. Annu. Rev. Nutr. 22:483-504. 